\title{
A REVIEW ON EFFECT ON PROPERTIES OF AL-SIC COMPOSITES FABRICATED BY STIR CASTING METHOD
}

\author{
N. S. Kalyankar', R. D. Shelke ${ }^{2}$, D. D. Barkul ${ }^{3}$ \\ ${ }^{1}$ Student at M. E. (Mechanical Manufacturing), Everest College of Engg. \& Tech., Aurangabad, Maharashtra, India. \\ nskalyankar@live.com \\ ${ }^{2}$ Head and Asso. Prof. at Dept. of Mechanical Engineering, Everest College of Engg. \& Tech., Aurangabad, \\ Maharashtra, India. \\ rahuldshelke@rediffmail.com \\ ${ }^{3}$ Student at M. E. (manufacturing), MGM's J. N. E. C., Aurangabad, Maharashtra, India. \\ nandadeep01@gmail.com
}

\begin{abstract}
Aluminum metal matrix composite made their impression in various applications because of their higher mechanical and physical properties along with high strength to weight ratio. This review paper focuses on the change in mechanical properties of various AL/SiC composites fabricated by using stir casting method. For this purpose various AL alloys are considered along with reinforcement of $\mathrm{SiC}$ with different wt\% and different particle sizes, variations in process parameters of stir casting are also made and taken into consideration. Effect of SiC reinforcement in different AL alloys on mechanical properties like hardness, tensile strength, compression strength, yield strength, \% elongation are discussed in detail.
\end{abstract}

Keywords: AL/Sic, Hardness, Tensile Strength, Wear Resistance, MMCs

\section{INTRODUCTION}

Metal matrix composites are the materials in which metal is used as a matrix material and reinforcement of metal, ceramic or organic compound is done. Some of the requirements of applications cannot be fulfilled by metal at this stage it becomes necessary to enhance required properties of metal that's why reinforcement of various materials is done. The requirement of various applications such as automobiles, aircraft, space industries and many more are fulfilled by AL MMCs. To increase properties of AL alloys reinforcement of materials like SiC, Al2O3, Boron carbide, Zircon, Fly ash etc. is made. The reinforcement is done in the form of particles, discontinuous fibers and continuous fibers [19]. The use of the reinforcement depends on the requirement of properties; Sic and $\mathrm{Al} 2 \mathrm{O} 3$ are most widely used reinforcements in case of AL alloys [17]. For the fabrication of AL MMC two routes are followed those are Liquid state fabrication route and solid state fabrication route. In liquid state fabrication route Stir casting, Squeeze casting, Compo casting or Rheocasting, Liquid metal infiltration, Spray casting, In-situ processing, Ultrasonic assisted casting techniques employed while in solid state fabrication route Powder metallurgy, Diffusion bonding, Vapor deposition technique, Friction stir processes are employed. Among these techniques stir casting is least expensive, attractive, flexible, simple and can be applied to large quantity production with commercial aspects [16], therefore it is widely accepted for fabrication of AL MMCs.

\section{Objectives}

The main objective of this review paper is to discuss the various properties of the AL alloys also the effect of the reinforcement of $\mathrm{SiC}$ on the properties when composite material is fabricated by using Stir casting method.

\section{PROPERTIES}

\section{A. Hardness}

Hardness is the resistance of a material to localized deformation. The term applies to deformation from indentation, scratching, cutting or bending. Hardness measurements are widely used for quality control of materials [14]. Rockwell hardness test and Vickers hardness test are the tests mostly used for checking the hardness of the materials [1] [8].

\section{B. Tensile Strength}

Tensile strength is the capacity of a material or structure to withstand loads tending to elongate, as opposed to compressive strength, which withstands loads tending to reduce sizes. Universal testing machines are used for calculating tensile strength of a material. [2] [3].

\section{Impact strength}

Impact strength is the ability of a material to absorb energy and physically deform without fracturing. It is determined with a Charpy or Izod test. For both test, the specimen is broken by a single overload event due to the impact of the pendulum. A stop pointer is used to record how far the pendulum swings back after fracturing the specimen. The 
impact toughness of a metal is determined by measuring the energy absorbed in the fracture specimen [14].

\section{Density}

Density is its mass per unit volume. The densities of the prepared specimens were investigated experimentally by the Archimedean's principle using sensitive electronic weighing machine having L. C. of $0.1 \mathrm{mg}$, with a beaker of $100 \mathrm{ml}$ distilled water [4].

\section{E. Wear}

Wear is caused by different sets of microscopic interactions between surfaces of mechanical contact when rubbed against each other. Wear is the progressive removal of material from the surface caused by microscopic removal mechanisms in sliding or rolling contact a counter surface [1]. Wear is calculated by using Pin-on-Disc method [6].

\section{F. Corrosion}

Corrosion is an irreversible interfacial reaction of a material with its environment which results in consumption of the material or in dissolution into the material of a component of the environment high-strength steel. It is based on weight loss determinations and provides a quantitative measure of the relative performance of the material evaluated [14].

\section{STIR CASTING}

There are two routes of fabrication of composite material those are Liquid state and Solid state fabrication. Solid state fabrication route is economical that's why it is most preferred. Stir casting is one of the liquid state methods of fabrication of composite material. This method is now a day adopted in commercial areas due its various advantages such as simple in operation and economic consideration. In stir casting method reinforcement is done in the matrix material. In conventional stir casting matrix material is melted with the help of furnace and reinforcement is added in molten material. This material is further stirred with the help of stirrer. After completion of mixing this metal casted according to conventional casting method. There are various matrix materials which can be used, if metal is used as matrix material then it is called as metal matrix composites. Reinforcement can be done in three ways particle reinforcement, short fiber reinforcement and continuous reinforcement [19]. The various parameters such as stirrers, furnaces, stirring speed, stirring time, preheating time of matrix material and reinforcement, feed rate, inert gas and pouring temperature are decided according to the matrix material and reinforcement material.

Conventional stir casting is now has various developments when compared with conventional stir casting. This development makes stir casting efficient, economical which opens the many ways in research work related with composite materials.

\section{REVIEW}

Balasubramanian et al. [2015] fabricated metal matrix composite with matrix material as a AA 6063 and reinforcement material as sic with different wt. \% of 0,5 , 10,15 by using stir casting method. When he compared properties like hardness, tensile strength and wear resistance of composite material with matrix material AA 6063 he found that the properties of composite material increases with increase in wt. \% of sic. Hardness for the specimens with $0,5,10,15 \%$ of $\mathrm{SiC}$ found 55.8, 64.17, 71.93, 86.07 $\mathrm{kgf} / \mathrm{mm}^{2}$ respectively. Tensile strength for the specimens with $0,5,10,15 \%$ of $\mathrm{SiC}$ found 140.94, 165.97, 180.61, $175.25 \mathrm{~N} / \mathrm{mm}^{2}$ respectively. [1].

J. Jebeen Moses et al. [2014] in his studies fabricates aluminum metal matrix composite with matrix material AA 6061 and $\mathrm{SiC}$ as a reinforcement material with wt. \% of 0,5 , 10 , and 15 by using stir casting method. When he compared hardness and tensile strength of composite material with matrix material AA 6061, properties increased as the wt. \% of $\mathrm{SiC}$ increases. Hardness of the material increases up to $133.33 \%$ as compared with unreinforced AA 6061 while UTS increases up to $65.2 \%$ as compared with unreinforced AA 6061 alloy [2].

Md. Habibur Rahman et al. [2014] fabricated aluminum metal matrix composite by using pure $\mathrm{AL}$ as a matrix material and $\mathrm{SiC}$ as reinforcement with wt. \% of $0,5,10$, and 20 with the help of stir casting method. He added Mg 1 wt. $\%$ as a wetting agent. He conducted hardness test, tensile test and wear test on composites and base material. The result of the test shows that as the wt. \% SiC in material increases the properties increases. Hardness for the specimens with 0, 5, $10,20 \%$ of $\mathrm{SiC}$ found 24.50, 38.67, 42.30, 45.40 VHN respectively. Tensile strength for the specimens with $0,5,10$, $20 \%$ of $\mathrm{SiC}$ found 28.45, 59.36, 50.17, 77.56 Мpa respectively [3].

M.Vamsi Krishna et al. [2014] uses AL 6061 as a matrix material and $\mathrm{SiC}$ as a reinforcement material with wt. \% of 0 , 5, 10 and 15 along with Gr wt. \% 0, 5, 10 and 15 by using stir casting method. He compared hardness test UTS of composites. He found that UTS of $\mathrm{AL} / \mathrm{SiC} / \mathrm{Gr}$ is more than that of $\mathrm{AL} / \mathrm{SiC}$ while density of $\mathrm{AL} / \mathrm{SiC}$ is more than that of AL/SiC/Gr. Density for the specimens with 5, 10, $15 \%$ of $\mathrm{SiC}$ found $2.70,2.71,2.73 \mathrm{gm} / \mathrm{cc}$ respectively while densities for the specimens with $5,10,15 \%$ of $\mathrm{SiC} / \mathrm{Gr}$ found 2.66, $2.64,2.63 \mathrm{gm} / \mathrm{cc}$ respectively. Tensile strength for the specimens with 5, 10, $15 \%$ of $\mathrm{SiC}$ found 132.34, 143.46, $150.95 \mathrm{Mpa}$ respectively while tensile strength for the specimens with $5,10,15 \%$ of $\mathrm{SiC} / \mathrm{Gr}$ found $144.73,173.39$, 192.45 Mpa respectively [4].

David Raja Selvam. J et al. [2013] used stir casting method for the fabrication of aluminum metal matrix composite. He used AL 6061 as a matrix material and $\mathrm{SiC}$ as a reinforcement material wt. $\%$ of 7.5 and 10 along with fly ash constant wt. $\%$ 7.5. After conducting different property tests like hardness, tensile strength, thermal co-eff. of expansion, he found that reinforcement materials enhances the properties of matrix material as the wt. \% increases. Ultimate tensile strength of the material increases from 173 Mpa to $213 \mathrm{Mpa}$ as the wt. \% of Sic increases with constant 
fly ash wt. \%. Thermal co-eff. of expansion of Sic \& fly ash composite is $3.25 \mathrm{X} 10^{\wedge} 6 /{ }^{\circ} \mathrm{c}$ while Thermal co-eff. of expansion of $\mathrm{AL} 6061$ is $23 \mathrm{X} 10^{\wedge} 6 /{ }^{\circ} \mathrm{c}$. Micro hardness increase from $69.53 \mathrm{HV}$ to $78.8 \mathrm{HV}$ while macro hardness increases from 49.4 $\mathrm{BHN}$ to 57.21 $\mathrm{BHN}$ [5].

Satyanarayen et al. [2015] fabricates aluminum metal matrix composite by using stir casting method. For this purpose he took $\mathrm{AL} \mathrm{LM}-25$ as a matrix material and $\mathrm{SiC}$ as a reinforcement material with wt. $\%$ of 3,6 , and 9 . He conducted property tests like hardness test, tensile test, and wear test on composites and matrix material. As a result he found increment in properties of material as the wt. \% of $\mathrm{SiC}$ increases. Hardness of the materials with 0, 3, 6 and 9 wt. \% of $\mathrm{SiC}$ found 60.3, 73.3, 76.27 and 77.27 respectively [6].

Ajay Anand et al. [2015] found improvement in properties when he fabricated an aluminum metal matrix composite by using stir casting method. He used AL 6061 as a matrix material and formed a composite by reinforcing $\mathrm{SiC}$ in it with wt. $\%$ of 2, 4, 6 and 8 . His results show that hardness, tensile strength and compression strength increases with increase in wt. \% of SiC. Hardness of the materials with 0,2 , 4, 6 and 8 wt. \% of $\mathrm{SiC}$ found 65, 66.3, 67.6, 68.8 and 67.8 respectively. Compression strength of the materials with 0,2 , 4, 6 and 8 wt. \% of $\mathrm{SiC}$ found 496.71, 775.72, 781.08, 693.06 and 656.23 Mpa respectively. Tensile strength of the materials with $0,2,4,6$ and 8 wt. \% of $\mathrm{SiC}$ found 147.504, $143.383,142.736,152.866,136.320 \mathrm{Mpa}$ respectively. Hardness is highest at $6 \%$, compression strength is highest at $4 \%$, and tensile strength is highest at $6 \%$ [7].

Arokiasamy S et al. [2015] fabricated aluminum metal matrix composite with matrix material AL 7075 and reinforcement of $\mathrm{SiC}$ with wt. \% constant but different particle sizes as 75, 88, 105 and $250 \mu \mathrm{m}$ by using stir casting method. He found improvement in properties of the material. Ultimate tensile strength of AL 7075 found $150 \mathrm{~N} / \mathrm{mm}^{2}$ while Ultimate tensile strength of AL 7075 composite found $165 \mathrm{~N} / \mathrm{mm}^{2}$ [8].

M.A. Hassan et al. [2014] fabricated aluminum metal matrix composite by using stir casting method with AL 6063 as a matrix material and $\mathrm{SiC}$ as a reinforcement wt. \% of 10, 20, 30,40 and 50. He conducted different property tests like hardness test, tensile test, compression test and impact test. He concluded that properties of the material increases with increase in wt. $\%$ of SiC. Tensile strength of the material increases from 131.23 Mpa to 194.60 Mpa. Compressive strength of the material increases from 103.70 Mpa to 167.15 Mpa. Impact strength of the material increases from 140.09 $\mathrm{KJm}-2$ to $250.37 \mathrm{KJm}-2$. Hardness of the material increases from $39.78 \mathrm{BHN}$ to $56.46 \mathrm{BHN}$ [9].

Marlon Jones Louis [2014] fabricated aluminum metal matrix composite by using stir casting method. He used AL 2024 as a matrix material and $\mathrm{SiC} 10$ wt. \% along with $\mathrm{Gr} 5$ wt. $\%$ as reinforcement. He compared hardness, tensile strength and yield strength of composite material and concluded that properties are increased because of reinforcement. Yield strength of the AL 2024 found $75 \mathrm{KN}$ while $95.10 \mathrm{KN}$ of the AL 2024 (10\% SiC + 5\% Gr.). Tensile strength of the AL 2024 found $93 \mathrm{KN}$ while 98.34 $\mathrm{KN}$ of the AL 2024 (10\% SiC + 5\% Gr.). Hardness of the AL 2024 found $47 \mathrm{BHN}$ while $57 \mathrm{BHN}$ [10].

Srinivasa. K et al. [2014] fabricated aluminum metal matrix composite with matrix material AL LM-6 and reinforcement material as $\mathrm{SiC}$ with wt. \% 0, 5, 10 and 15 along with $\mathrm{Mg} 1$ wt. $\%$ as a wetting agent. After conducting various property tests like hardness test and wear test he concluded that properties of the material increases with increase in wt. of SiC. Hardness of the material with Si Cwt. \% 0, 5, 10 and 15 found 55.68, 61.47, 67.72 and 76.77 $\mathrm{BHN}$ respectively [11].

N.Subramani et al. [2014] fabricated aluminum metal matrix composite by using stir casting method. He used AL 2024 as a matrix material and $\mathrm{SiC}$ as a reinforcement material with wt. $\%$ of 0,10 and 15 . After conducting property tests like hardness test and tensile test he found that hardness and tensile strength of composite material is greater than matrix material and increases with increase in wt. of SiC. Hardness of the composite material with 10 and 15 wt. \% SiC found 48 and $530 \mathrm{RHN}$ respectively. Tensile strength of the composite with 10 and 15 wt. $\%$ of SiC found 270.9 and $228.6 \mathrm{~N} / \mathrm{mm} 2$ respectively [12].

Akhilesh Jayakumar et al. [2014] used AL LM-25 as a matrix material and $\mathrm{SiC}$ as reinforcement material with wt. \% 5 along with $\mathrm{Mg}$ wt. \% 1 as a wetting agent for fabricating aluminum metal matrix composite by using stir casting method. He conducted hardness test and tensile test and concluded that reinforcement of $\mathrm{SiC}$ increases the properties of matrix material [13].

Dinesh M. Pargunde et al. [2013] used Al [98.41\%] as a matrix material, $\mathrm{SiC}$ as a reinforcement material with wt. \% $5,10,15,20,25$ and 30 for fabrication of aluminum metal matrix composite by using stir casting method. He conducted hardness test and corrosion test on composite material and matrix material and concluded that properties of the material increases up to $25 \mathrm{wt}$. \% of $\mathrm{SiC}$ later increase in wt. \% of $\mathrm{SiC}$ decreases the properties of the material. Hardness of the material with $0,5,10,15,20,25,30$ wt. $\%$ of $\mathrm{SiC}$ found $30.80,39.33,40.40,42.40,43.60,44.80$ and 41.60 respectively. Impact strength of the material with $0,5,10$, $15,20,25,30$ wt. $\%$ of $\mathrm{SiC}$ found $10.67,22.67,24.00,27.33$, $31.33,35.33$ and 32.00 respectively. Corrosion resistance of the material with 25 wt. \% $\mathrm{SiC}$ found highest and it is $4.88822 \mathrm{~mm} / \mathrm{month}$. The result of the experiment shows that the composite material with 25 wt. $\% \mathrm{SiC}$ has greater properties among the all compositions [14].

B. P. Samal et al. [2013] fabricated aluminum metal matrix composite by using stir casting method. This fabrication includes $\mathrm{AL}$ as a matrix material along with $\mathrm{SiC}$ wt. \% 10 as a reinforcement and $\mathrm{Mg}$ wt. \% 3 as a wetting agent. He conducted different property tests like hardness test, tensile test, yield strength, UTS, elastic modulus and \% elongation. Form these tests he concluded that reinforcement increases 
the properties of the matrix material as well increase in wt. \% of reinforcement increases the properties. Yield strength of the composite (AL-Mg 3 wt. \%) found $91 \mathrm{Mpa}$ and $136 \mathrm{Mpa}$ of the composite (AL-Mg 3 Wt. \%, Sic $10 \mathrm{Wt}$. \%). Tensile strength of the composite (AL-Mg $3 \mathrm{wt}$. \%) found 224Mpa and 293Mpa of the composite (AL-Mg $3 \mathrm{Wt} \%$, Sic $10 \mathrm{Wt}$. $\%$ ). Elastic modulus of the composite (AL-Mg 3 wt. \%) found $62 \mathrm{Gpa}$ and $77 \mathrm{Gpa}$ of the composite (AL-Mg $3 \mathrm{Wt}$. \%, Sic $10 \mathrm{Wt}$ \%). \% elongation of the composite (AL-Mg $3 \mathrm{wt}$. $\%$ ) found 21.25 and 6.7 of the composite (AL-Mg 3 Wt. \%, Sic 10 Wt. \%). Yield strength, Ultimate tensile strength and Elastic modulus increased by $49 \%, 31 \%$ and $24 \%$ respectively. The $\%$ elongation decreased by $68 \%$ shows up to $6 \%[15]$.

\section{PROPOSED WORK}

Metal matrix composites found their impression in various applications due to their properties because of this research in this particular area is very necessary and important. Metal matrix composites can replace the matrix material for this purpose MMCs must be fabricated with various combinations of matrix material and reinforcement materials. From this review paper it can be seen that there are various combinations of matrix material and reinforcement can be fabricated and studies can be conducted on properties of this MMCs so that replacement for the conventional materials can be done and obtain improved applications with better life of applications.

\section{CONCLUSION}

As far as the recent scenario of composite material manufacturing is concerned stir casting is most effective and efficient in all the aspects such as cost, simplicity of operation, distribution of reinforced particles etc. are superior over methods available for manufacturing of composite materials. Stir casting method is suitable up to $30 \mathrm{wt} \%$ of reinforcement material.

Most of the AL alloys supports the reinforcements of the material and due to this reinforcement properties of the matrix material increases up to some extent some of the alloys supports reinforcements up to $50 \%$ of wt. \% but increase in properties is limited up to some wt. \% for e.g. In case of AL (98.41\%) it is found that properties get decreased after wt $\%$ of $\mathrm{SiC}$ crosses $25 \%$.

\section{SUMMARY}

Stir casting is found very useful fabrication method for AL/SiC composite as far as cost and effectiveness is concerned.

Properties of the matrix material can be increased by increasing wt. $\%$ of reinforcement.

\section{REFERENCES}

[1]. Balasubramanian, R. Maheswaran Effect of inclusion of $\mathrm{SiC}$ particulates on the mechanical resistance behavior of stir-cast AA6063SiC composites. Materials and Design 65 (2015) 511-520.
[2]. J. Jobeen Moses, I. Dinaharan, S. Joseph Sekhar Characterization of sic particulate reinforced AL6061 produced via stir casting. Procedia Materials Science 5(2014) $106-112$.

[3]. Md. Habibur Rahman, H. M. Mamun Al, Rashed Characterization of silicon carbide reinforced aluminum matrix Composites Procedia Engineering 90 (2014) 103109.

[4]. M.Vamsi Krishna, Anthony M. Xavior an Investigation on the Mechanical Properties of Hybrid Metal Matrix Composites Procedia Engineering 97 (2014) 918 -924.

[5]. David Raja Selvam. J, Robinson Smart, D. S. Dinaharan. I, Synthesis and characterization of Al6061-Fly Ashp-SiCp composites by stir casting and compocasting methods. Energy Procedia 34 (2013) 637 - 646.

[6]. Satyanarayen, Dominic Roystan, M.ShreesaravananBalaguru, C.Devanathan A Study on Mechanical Properties of Aluminum LM25- Sic Composites Fabricated Using Stir Casting Technique. ISSN 2394-3777 (Print) ISSN 23943785 (Online) Vol.II, Special Issue XXII, February 2015.

[7]. Ajay Anand, S.S Chikkadeve Gowda Characterization of Aluminium-Silicon Carbide Composite using Stir Casting Technique IJSRD - International Journal for Scientific Research \& Development| Vol. 3, Issue 08, 2015 | ISSN (online): 2321-0613.

[8] Arokiasamy S., Anand Ronald B, Pruthivirajan M, Mohan D Investigation of Mechanical Properties of Aluminum Alloy 7075-Silicon carbide Particulates reinforced Metal Matrix Composites. International Conference on Recent Advancements in Materials (ICRAM) 2015.ISSN: 0974-2115.

[9]. M.A. Hassan, T.C. Ofor, A.M. Usman, N.Y. Godi Development of Aluminum Metal Matrix Composite Using Stir Casting Method The International Journal OfEngineering And Science (IJES) || Volume || 3 || Issue || 8 || Pages || 36-39 || 2014 ||ISSN (e): 2319 - 1813 ISSN(p): $2319-1805$

[10]. Marlon Jones Louis, Fabrication, testing and analysis of aluminum 2024 Metal matrix composite. International journal of research in aeronautical and mechanical engineering. Volume 2, Issue 4, April-2014, Pages 29-37.

[11]. Srinivasa.K, Devaraj.M.R, Yathisha.N, Manjunath.H.S. Microstructure analysis and wear behavior of al based metal matrix composite reinforced with ceramic particles. IJRET: International Journal of Research in Engineering and Technology eISSN: 2319-1163 | pISSN: 2321-7308

[12]. N.Subramani, M.Balamurugan, K.Vijayaraghavan Mechanical Behavior of Al-SiC Composites Prepared By Stir Casting Method International Journal of Innovative Research in Science, Engineering and Technology Vol. 3, Issue 3, March 2014 ISSN: 2319-8753

[13]. Akhilesh Jayakumar -Mahesh Rangaraj Property Analysis of Aluminium (LM-25) Metal Matrix Composite International Journal of Emerging Technology and Advanced Engineering (ISSN 2250-2459, ISO 9001:2008 Certified Journal, Volume4, Issue 2,February 2014)

[14]. Dinesh M. Pargunde, Prof. Gajanan N. Thokal, Prof. Dhanraj P. Tambuskar, Mr. Swapnil S. Kulkarni Development of aluminum based metal matrix composite 
(AlSiC) International Journal of Advanced Engineering Research and Studies (AlSiC) EISSN2249-8974

[15]. B. P. Samal, S. C. Panigrahi, B. Sarangi Use of Modified Stir Casting Technique to Produce Metal Matrix Composites International Journal of Engineering and Technical Research (IJETR) ISSN: 2321-0869, Volume-1, Issue-9, November 2013

[16].C. Saravanan K Subramanian, D B Sivakumar, M. Sathyanandhan, R Sankara Narayanan, FABRICATION OF ALUMINIUM METAL MATRIX COMPOSITE AREVIEW National Conference On Recent Trends And Developments In Sustainable Green Technologies Journal of Chemical and Pharmaceutical Sciences ISSN: 0974-2115

[17]. B. Vijaya Ramnath, C. Elanchezhian, RM. Annamalai, S.Aravind,T. Sri AnandaAtreya, V. Vignesh and C.Subramanian ALUMINIUM METAL MATRIX COMPOSITES - A REVIEW

[18]. Tabish Qamar Hashmi Liquid State Methods of Producing Metal MatrixComposites: A Review Article IJRMET Vol. 5, Issue 1, November 2014 - April 2015ISSN: 2249-5762 (Online) | ISSN: 2249-5770[

[19]. Bhaskar Chandra Kandpal, Jatinder Kumar, Hari Singh Production Technologiesof Metal Matrix Composite: A Review IJRMET Vol. 4, Issue 2, Spl - 2 May -October 2014 ISSN: 2249-5762 (Online) | ISSN: 2249-577014Vol.2

Issue. 4 